\title{
Erratum to: Antinociceptive interaction of gabapentin with minocycline in murine diabetic neuropathy
}

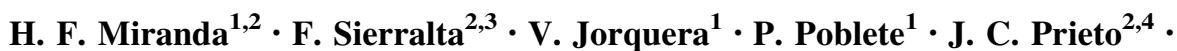
V. Noriega ${ }^{1,4}$

Published online: 12 June 2017

(C) Springer International Publishing AG 2017

Erratum to: Inflammopharmacol (2017) 25:91-97 DOI 10.1007/s10787-017-0308-5

Unfortunately, one of the co-author affiliation was wrongly published in the original publication.

The correct affiliation is given below:

J. C. Prieto ${ }^{2,4}$

The online version of the original article can be found under doi:10. 1007/s10787-017-0308-5.

H. F. Miranda

hmiranda@med.uchile.cl

1 Faculty of Medicine, School of Pharmacy, Andres Bello University, República 590, Santiago, Chile

2 Pharmacology Program, ICBM, Faculty of Medicine, University of Chile, Independencia 1027, Santiago, Chile

3 Faculty of Odontology, Finis Terrae University, Pedro de Valdivia 1509, Providencia, Chile

4 Cardiovascular Department, Clinic Hospital, University of Chile, Santos Dumont 999, Santiago, Chile 